\title{
Load Determination and Selection of Transformer Substations' Optimal Power for Tasks of Urban Networks' Development
}

\author{
Svetlana Guseva, Riga Technical University, Olegs Borscevskis, Riga Technical University, \\ Nataly Skobeleva, Riga Technical University, Lubov Kozireva, Riga Technical University
}

\begin{abstract}
In this paper an approach to solving the some problem of urban 110/10-20 kV network development until 2020 in Riga city in conditions of information uncertainty are considered. The following steps are considered in the paper: forecast of the total load of the Riga city until 2020, the definition of loads of existing and new substations until 2020, choice of $110 / 10-20 \mathrm{kV}$ substations' the optimal power, determine the location of new substations.
\end{abstract}

Keywords: network development, forecasting, urban substations, geometrical templates.

\section{INTRODUCTION}

The urban power supply system (UPSS) is system of continuous development. The elements of such system are objectives of long-term or medium-term design. To solve the problems of development on such a prospect is not accurate background information and detailed guidelines projected subjects. It means that the challenges of development occur in conditions of incomplete and uncertain information.

The UPSS of a major city is, as rule, a component of the regional or the state power system. Since the power supply system of Riga city is an integral part of the Latvian Power System and the largest consumer of electricity in state. Every UPSS is formed historically with a certain hierarchy of voltages. There are the stages or subsystems of hierarchical structure: the external supply system of the city with voltage $330 \mathrm{kV}$ or higher, the internal supply system with voltages $110-20-10-0.4 \mathrm{kV}$ and the aggregate of urban consumers. Connections between subsystems are carried out through highvoltage transformer substations (TS) and networks of the corresponding levels of the voltage hierarchy.

For guaranteeing of viability of such large object as the major city should be the systems analysis and general approach to construction, formation of basic parameters of networks, the further development of separate subsystems and all UPSS as a whole.

This paper considers an approach to solving the some problem of $110 / 10-20 \mathrm{kV}$ network development of Riga city until 2020. The following steps are considered in the paper: forecasting of the total load for the Riga city until 2020, the definition of loads of existing and new substations until 2020, definition choice of $110 / 10-20 \mathrm{kV}$ substations' the optimal power, choice the location of new substations.

\section{LOAD FORECASTING FOR RIGA CITY}

The decision about further development of separate subsystems of UPSS should be based on a forecast of longterm or medium-term consumption of electricity in the Latvian Power System (Latvenergo) and perspective total load of the Riga city. The forecasting of electrical load for Latvian Power System and Riga city is fulfilled for the period from 2008 till 2020. The forecast is made in the light of the prevailing economic situation in the state in recent years. The analysis of measurements from 2000 to 2008 is made and subsequent forecast is fulfilled. The forecast of consumption of the Latvian Power System in graphical view can be seen in Fig. 1.

For forecasting of Riga electrical load must take into account:

- the actual load of $110 \mathrm{kV}$ transformer substations by measurements from 2000 to 2008;

- $\quad$ load of consumers growing by years;

- marketable power of new objects;

- technical possibilities to cover new declared powers and another factors.

The variants of forecast are taken for:

- $3 \%$-percent year load growing, beginning from 2008 till 2020 in favorable scenario of the economic development (AS Latvenergo forecast till beginning of crisis of the economics);

- $2 \%, 1.7 \%, 1.3 \%$ and $1.1 \%$-percent year load growing in disadvantaged scenario of the economic development, without excluding the period of recession in the economy;

- $2 \%, 1.7 \%, 1.3 \%$ and $1.1 \%$-percent year load growing in disadvantaged scenario of the economic development with the period of recession from 2008 till 2012 without load growing and with improvement of economic situation since 2012 .

Graphical forecasting of Riga city can be seen in Fig. 2 for different scenarios of the economic development. The deteriorating economic situation leads to the need to periodically adjust the previously made predictions. 


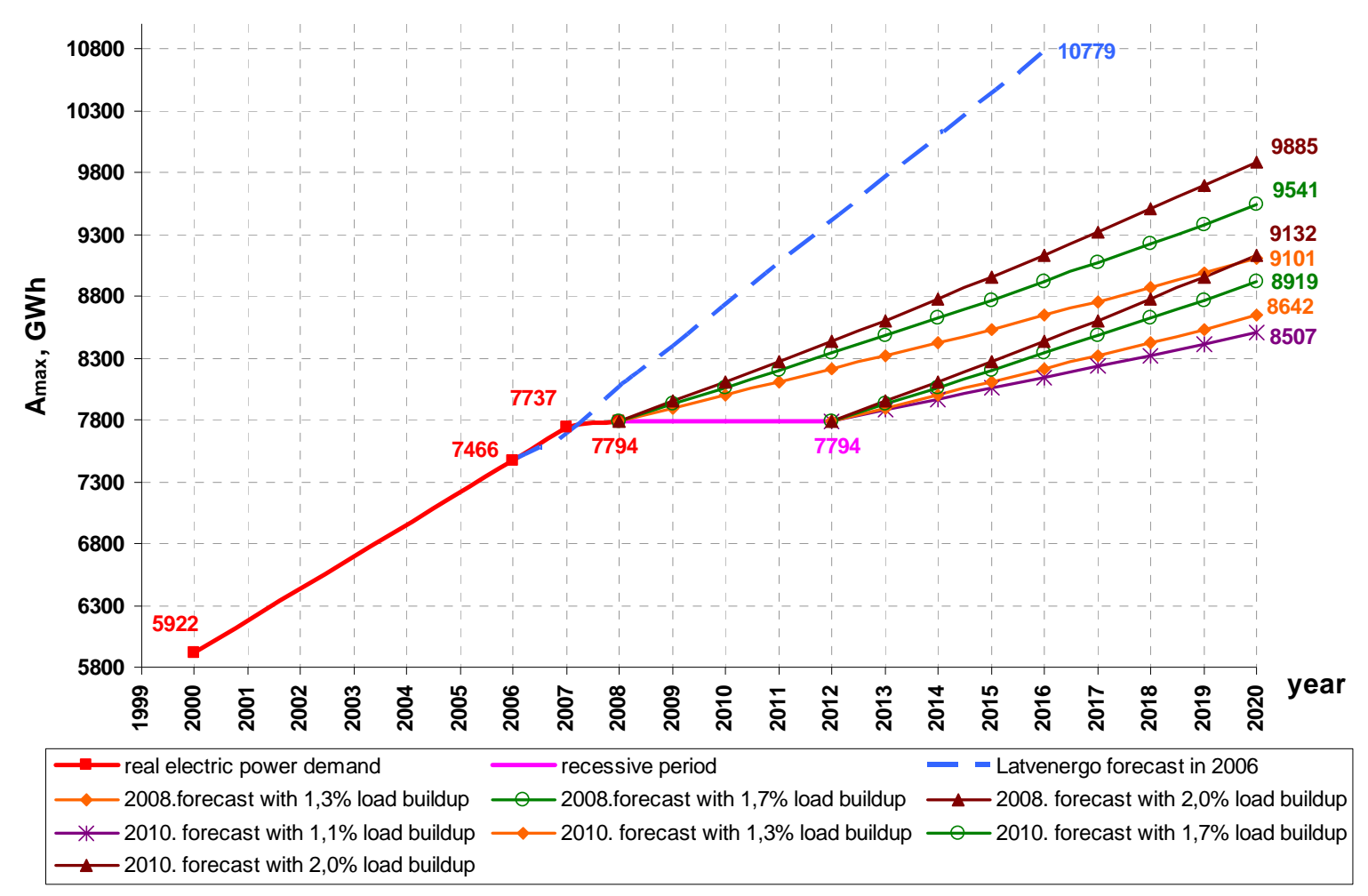

Fig. 1. The forecast of Latvian Power System consumption of electricity

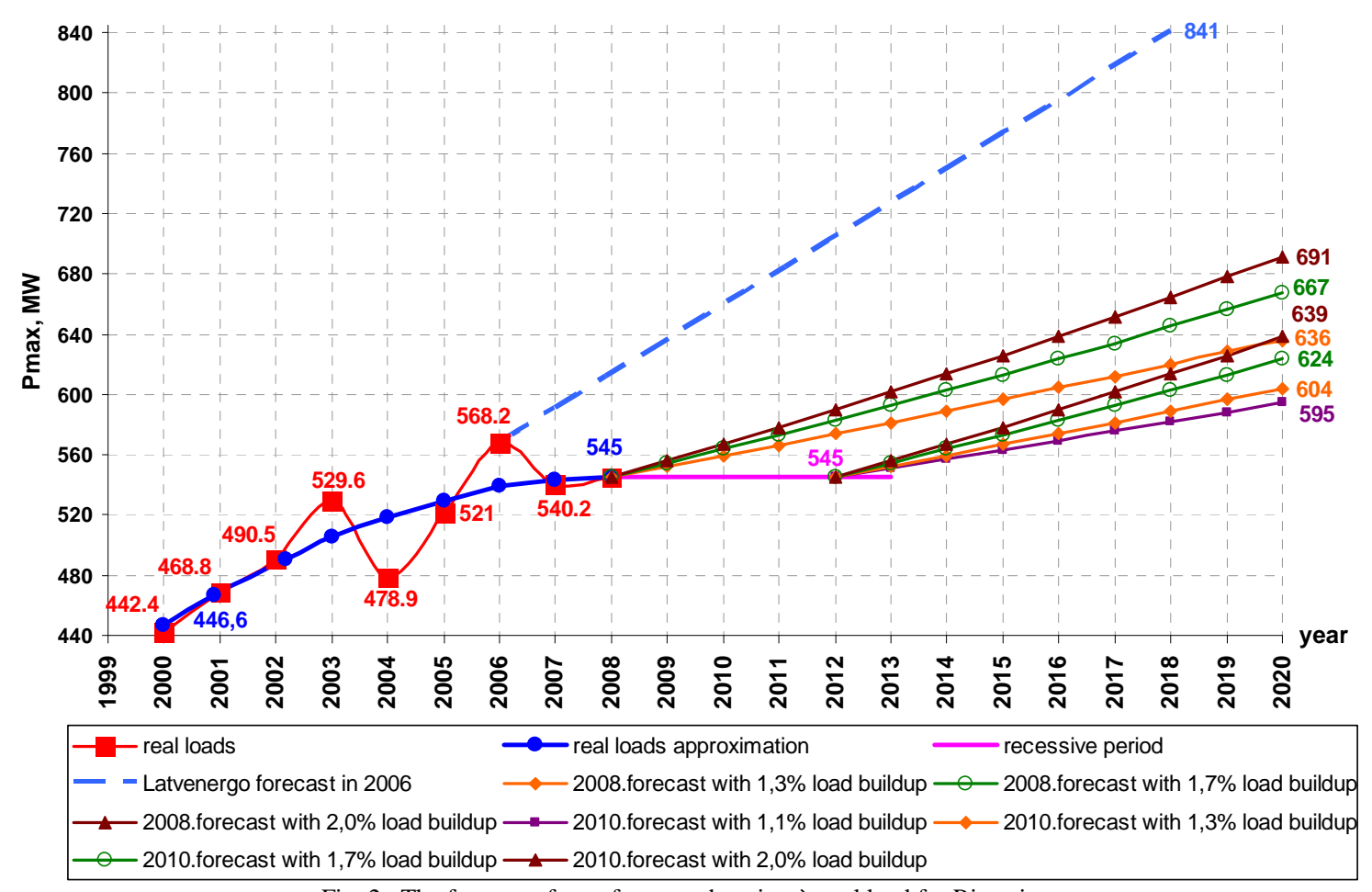

Fig. 2. The forecast of transformer substations` total load for Riga city 


\section{LOAD OF TRANSFORMER SUBSTATION AND LOAD DENSITY IN ITS SERVICE AREA}

The load of transformer substations is formed by different groups of urban consumers. The total load of consumers at each stage of hierarchical structure (Fig.3) should be covered with sufficient TS power, taking into account the required reserve, to guarantee normal quantity of energy supply to consumers.

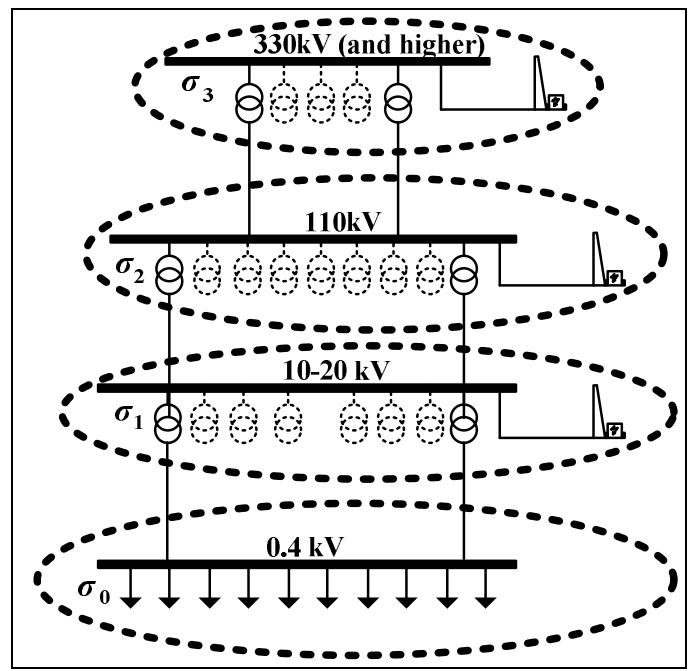

Fig. 3. The hierarchy of voltage levels and load densities in the urban networks

The total electrical load of the city can be found like

$$
S_{\text {pils }}=k_{0, T S} \sum_{i=1}^{n_{T S}} S_{T S, i}=k_{0, T S} \sum_{i=1}^{n_{T S}} n_{i} \cdot \beta_{i} \cdot S_{r, i}
$$

where $S_{\text {pils }}$ is the total electrical load of the city in the appointed year;

$S_{T S, i}$ is $i$ - transformer substation load in the appointed year, MVA;

$k_{o, T S}$ is the simultaneity factor of transformers' load maximum, depending of $110 \mathrm{kV}$ TS quantity; $n_{i}$ is quantity of transformers in $i \mathrm{TS}$;

$\beta_{i}$ is load factor of each transformer in TS;

$S_{r, i}$ is transformer's mounted rated power in $i$ TS, MVA;

$n_{T S}$ is transformer substations' quantity in the city area.

The average load density in the city on a given voltage level is:

$$
\sigma_{a v}=\frac{S_{c i t y}}{\Pi_{c i t y}},
$$

where $\sigma_{a v}$ is the average load density in the network, $\mathrm{MVA} / \mathrm{km}^{2}$;

$\Pi_{\text {city }}$ is the territory of the city allocated for building, $\mathrm{km}^{2}$.

If the load densities in the service areas of separate substations $\Pi_{T S, i}$ are different, then the corrected average load density in the city can be defined as:

$$
\begin{array}{r}
\sigma_{a i . c r}=\frac{k_{o j}\left(S_{T S, 1}+S_{T S, 2}+\ldots .+S_{T S, i}\right)}{k_{r e c}\left(\Pi_{T S, 1}+\Pi_{T S, 2}+\ldots .+\Pi_{T S, i}\right)}= \\
=\frac{k_{o j}\left(\sigma_{T S, 1} \Pi_{T S, 1}+\sigma_{T S, 1} \Pi_{T S, 2}+\ldots .+\sigma_{T S, i} \Pi_{T S, i}\right)}{k_{r e c}\left(\Pi_{T S, 1}+\Pi_{T S, 2}+\ldots .+\Pi_{T S, i}\right)}
\end{array}
$$

where $k_{r e c}$ is the accepted recovering factor of TS service areas in real conditions.

The total service area of TS should be no less than general territory of city allocated for building (with the exception of water spaces, forest and park arrays etc.):

$$
\Pi_{\text {city }} \leq k_{\text {rec }} \cdot \sum_{i=1}^{n_{T S}} \Pi_{T S, i}
$$

In the real conditions the load densities in separate districts, micro districts of city and, also, in the service areas of separate substations are different. The load density in the service area of separate substation is:

$$
\sigma_{T S, i}=\frac{S_{T S, i}}{\Pi_{T S, i}}=\frac{n_{i} \cdot \beta_{i} \cdot S_{r, i}}{\Pi_{T S, i}} .
$$

The service area of transformer substation can be modeling every possible geometrical figure: a circle, a square, a correct hexagon. The most convenient model is a hexagon, which enables in regular intervals to fill territory of building by practically any form. This model of a service area TS is chosen in work as uniform model-template at the decision of questions of development for city networks. It is conditionally accepted, that the substation is placed in the center of a hexagon (in real circumstances it should not fall outside the limits the area of the hexagon).

Geometrical models-templates of substations`service areas in the form of correct hexagons are offered on Fig. 4, when the load densities in the service areas of separate substations are equal.

The correlations between basic geometrical sizes of the hexagon (models - templates), the main technical parameters of transformers and networks are determined for design of templates. 


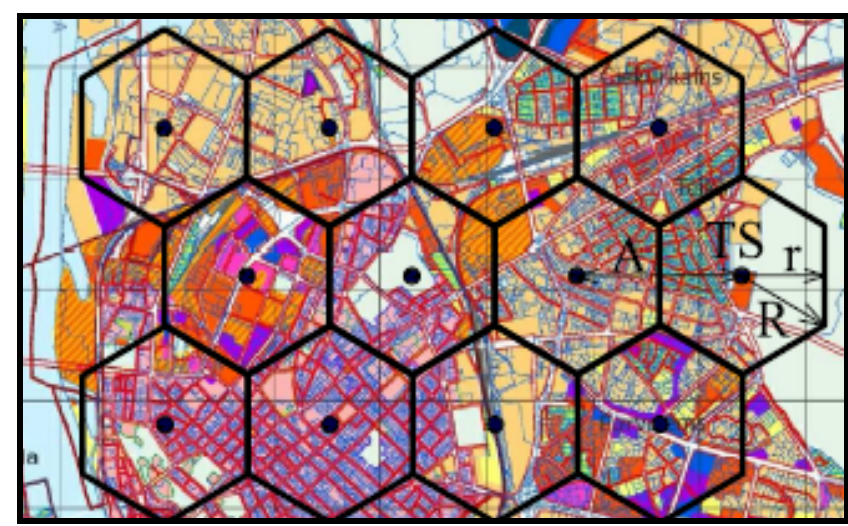

Fig. 4. The ideal model of TS location in the Masterplan of city

\section{LOAD DEFINITION OF TRANSFORMER SUBSTATION FOR THE PERIOD TILL 2020}

The maximal active electrical load of each existing transformer substations can be found with the help of expression:

$$
P_{2020}=P_{2008} \cdot\left(1+\frac{\alpha}{100}\right)^{t_{2}-t_{1}}+k_{1} \cdot k_{2} \cdot P_{p}
$$

where $\alpha$ is the medium growing of consumers' load per year;

$t_{2}$ is the final year of calculation period $\left(t_{2}=2020\right)$;

$t_{1}$ is the beginning year of load growing $\left(t_{l}=2008\right.$ or $t_{l}=2012$ in accordance with accepted calculation variant);

$P_{p}$ is the marketable power of consumer;

$k_{1}$ is the factor of simultaneity of load maximum $\left(k_{l}=0.8\right)$;

$k_{2}$ is the correction factor, which depends on marketable power of consumer and on uncertainty of connection term $\left(k_{2}=0.7\right)$.

The calculation algorithms for definition of transformer substations` loads are offered in Fig. 5 and implemented. The calculation algorithm is realized by program Microsoft EXCEL for each existing and perspective transformer substation.

TS service area (also the side of a hexagon) and its radius according with geometrical models-templates in the form of correct hexagons can be found by expressions:

$$
\begin{gathered}
\Pi_{T S, i}=2.6 \cdot R_{i}^{2}=\frac{n_{i} \cdot \beta_{i} \cdot S_{r, i}}{\sigma_{i}}, \\
R_{i}=0.62 \cdot \sqrt{\Pi_{T S, i}}=0.62 \cdot \sqrt{\frac{n_{i} \cdot \beta_{i} \cdot S_{r, i}}{\sigma_{i}}} .
\end{gathered}
$$

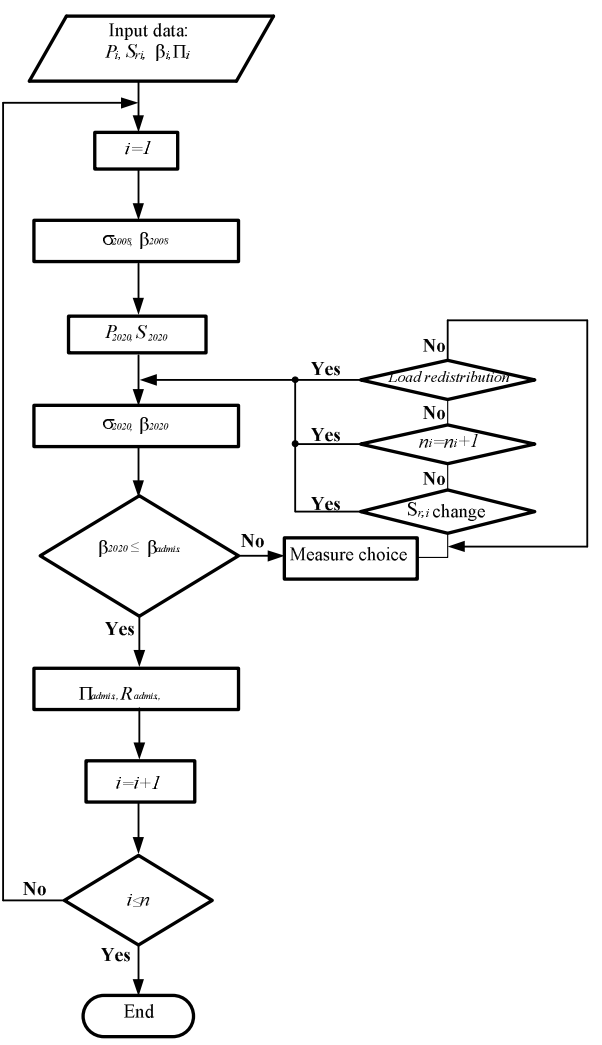

Fig. 5. The calculating algorithm of transformer substation loads

\section{V.OPTIMAL POWER OF TRANSFORMER SUBSTATION FOR EACH LOAD DENSITY}

For rational construction of power system it is necessary to determine the optimal power of substations for each voltage level. This is a complex and laborious task. In paper the choice of TS optimum power for the $110 \mathrm{kV}$ network on basis of variants ' comparison is made.

Total investments of variants $K_{\Sigma}$ can be found by expression:

$$
K_{\Sigma}=K_{T S \Sigma}+K_{T P \Sigma}+K_{A L \Sigma}+K_{V L \Sigma}
$$

where $K_{T S \Sigma}$ are capital investments for $110 / 10 \mathrm{kV}$ TS construction;

$K_{A L \Sigma}$ are capital investments of $110 \mathrm{kV}$ cable line for $110 / 10 \mathrm{kV}$ TS connection;

$K_{T P \Sigma}$ are capital investments for $10 / 0.4 \mathrm{kV}$ TS construction;

$K_{V L \Sigma}$ are $10 \mathrm{kV}$ cable line capital investments for $10 / 0.4 \mathrm{kV}$ TS connection.

Certain functions of the components can be calculated as follows:

$$
K_{T S \Sigma}=n_{T S} \cdot K_{T S},
$$

where $n_{T S}$ is the number of $110 / 10 \mathrm{kV}$ TS; 


$$
\begin{gathered}
K_{A L \Sigma}=\lambda_{A} \cdot A \cdot n_{T S} \cdot K_{i p A L}= \\
=1.7 \cdot 1.1 \sqrt{\Pi_{T S}} \cdot n_{T S} \cdot K_{i p A L}=\quad, \\
=1.9 \sqrt{\Pi_{T S}} \cdot n_{T S} \cdot K_{i p A L}
\end{gathered}
$$

where $\lambda_{A}$ is $110 \mathrm{kV}$ network configuration factor (loopthrough scheme adopted $\lambda_{A}=1.7$ );

$A$ is the theoretical distance between the $110 / 10 \mathrm{kV}$ substation adjacent;

$K_{i p A L}$ is $1 \mathrm{~km}$ of $110 \mathrm{kV}$ cable line construction costs;

$$
K_{T P \Sigma}=n_{T P} \cdot K_{T P} \cdot n_{T S},
$$

where $n_{T P}$ is $10 / 0.4 \mathrm{kV}$ TS quantity in one $110 / 10 \mathrm{kV}$ TS service area;

$K_{T P}$ is $10 / 0.4 \mathrm{kV}$ TS cost.

In addition:

$$
n_{T P}=\frac{\Pi_{T S}}{\Pi_{T P}}=\frac{S_{r, T S}}{k_{o, T P} \cdot S_{r, T P}}
$$

where $\Pi_{T P}$ is $10 / 0.4 \mathrm{kV}$ TS service area;

$S_{r, T P}$ is $10 / 0.4 \mathrm{kV}$ TS rated power;

$k_{o, T P}$ is factor of simultaneity at transformers' load maximum, depending of $10 / 0.4 \mathrm{kV}$ TP quantity;

$$
\begin{array}{r}
K_{V L \Sigma}=n_{T P} \cdot K_{i p V L} \cdot L_{V L}= \\
=n_{T P}\left(K_{i p V L} \cdot \lambda_{V} \cdot 1.1 \sqrt{\Pi_{T P}} \cdot n_{f i d}\right)= \\
=n_{T P} \cdot K_{i p V L} \cdot 3.3 \sqrt{\Pi_{T P}} \cdot \frac{n \cdot \beta \cdot S_{T S}}{S_{f i d}}
\end{array}
$$

where $K_{i p V L}$ is $1 \mathrm{~km}$ of $10 \mathrm{kV}$ cable line construction costs.;

$L_{V L}$ is length of new $10 \mathrm{kV}$ cable lines to connect TP;

$\lambda_{V}$ is $10 \mathrm{kV}$ network configuration factor (loop-

through scheme adopted $\lambda_{A}=2.5$ );

$\Pi_{T P}$ is TS service area;

$n_{\text {fid }}$ is $10 \mathrm{kV}$ feeder average number from TS;

$S_{\text {fid }}$ is $10 \mathrm{kV}$ feeder medium permeability

$\left(S_{\text {fid }}=2.5 M V A\right)$.

The optimum solution of function (9) is equal with the minimum of total investments of variants comparison. The results of calculations are shown in Fig. 6.

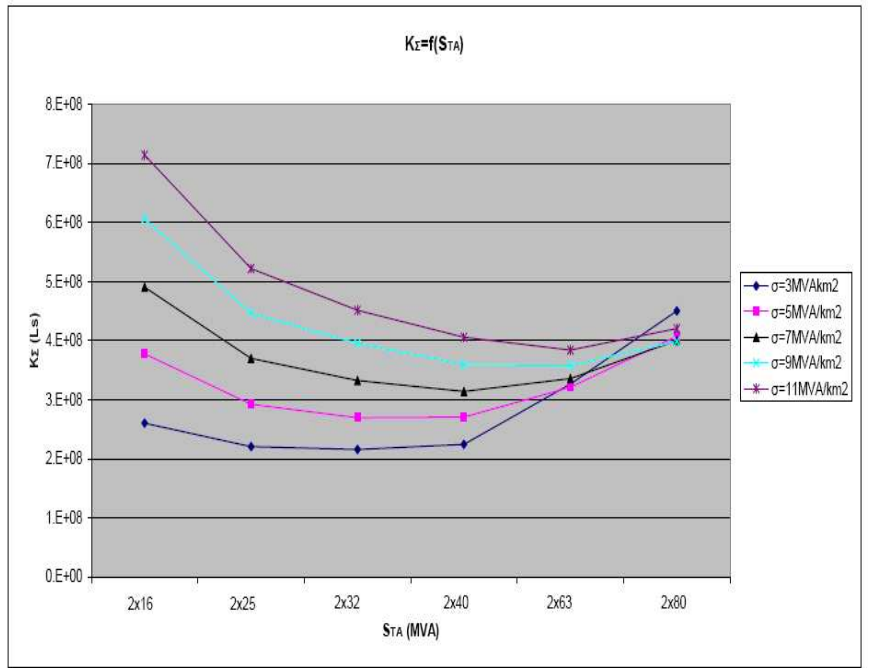

Fig. 6. Total investments of urban power supply system depending on the substation transformer power $K_{\text {sum }}=f\left(S_{T S}\right)$

On the basis of the results (Fig.6) followed that cities with a load density $\sigma=3-5 \mathrm{MVA} / \mathrm{km}^{2}$ is economically to use the TS with power in $2 \times 32$ MVA, with a load density $\sigma=5-9$ $\mathrm{MVA} / \mathrm{km}^{2}-2 \times 40$ MVA substation, with load density $\sigma=9$ MVA $/ \mathrm{km}^{2}-2 \times 63$ MVA substation, $\sigma>11 \mathrm{MVA} / \mathrm{km}^{2}-2 \times 80$ MVA substation.

All the consumers of a city must be rationally distributed among separate transformer substations according to their service area to provide qualitative power supply.

As example, the location of substations on the part of city's territory at Masterplan, when the load densities in the service areas of separate substations are different, is shown in Fig. 7.

Automation process of TS service areas placing on the map of the city is realized by means of Microsoft EXCEL calculation program and graphic computer program AutoCAD.

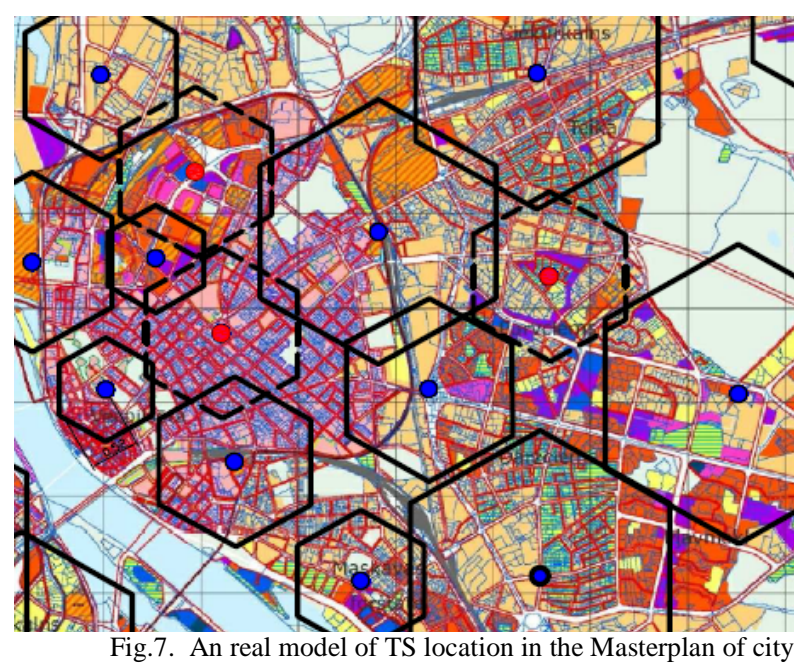


The proposed method and its implementation allow making decisions in development of networks on early design stages and choose a rational perspective plan in the conditions of uncertainty of the initial information.

In perspective power supply scheme of Riga, the location for all of theoretically possible TS and possibilities to connect them to existing or new $110 \mathrm{kV}$ lines for the realization of $110-330 \mathrm{kV}$ scheme development are foreseen.

\section{ACKNOLEDGEMENT}

This work has been supported by the European Social Fund within the project ,Support for the implementation of doctoral studies at Riga Technical University"

\section{REFERENCES}

[1] Krishans Z., „Fundamentals of Power Engineering Enterprises Managment," Riga, Riga Techical University, 1997. 122 p. (in Latvian).

[2] S.Guseva, N.Skobel̨eva, N.Breners, O.Borščevskis, „Service areas modelling of urban transformer substations," Proceedings of Riga Technical University, Power and Electrical Engineering, Ser.4, Vol. 24, Riga, 2009. p. 24 -31 (in Latvian).

[3] S.Guseva, O.Borscevskis, N.Skobeleva, N.Breners, „Load forecasting till 2020 of existing and perspective transformer substations in Riga," Proceedings of Riga Technical University, Power and Electrical Engineering, Ser. 4, Vol. 25, Riga, 2009. p. 77-80.

[4] S.Guseva, N.Skobeleva, N.Breners, O.Borscevskis, "Determination of service areas of urban transformer substations and distribution using geometrical templates", Latv. Journ. of Ph. and Techn. Sc., No 6, Riga, 2009, p.16-26.

[5] S.Guseva, N.Skobeļeva, N.Breners, O.Borscevskis, "Pilsētu transformatoru apakšstaciju apkalpes zonu modelēšana," Energéétika un elektrotehnika, Ser.4., Sēj. 24, Rīga, RTU, 2009, 24-31 lpp.

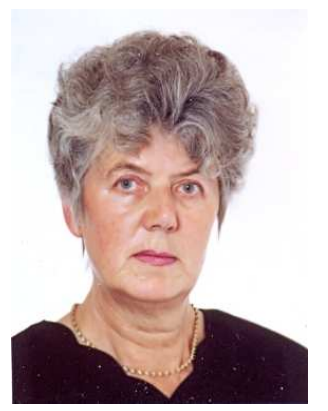

Svetlana Guseva received Dipl. Eng. from Riga Polytechnic Institute (RPI) in 1964, Cand. Techn. Sc. degree from Byelorussian Polytechnic Institute (BPI) in 1987 and Dr. Sc. Ing. degree in 1992 from Riga Technical University (RTU). She has been working in RTU (earlier RPI) from 1965, from 2003 she is Associated profesor of RTU. Her research include Power System Mathematical Simulation and Optimization.

Address: Kronvalda blv.,1,LV-1010, Riga,

Latvia

Phone: +371 7089938, fax: +371 7089931

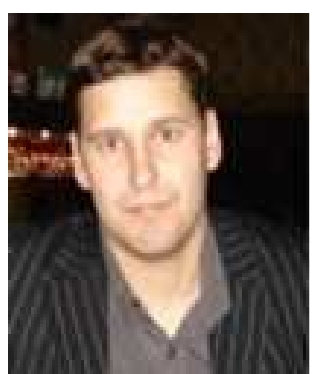

Olegs Borscevskis received Dipl. Eng. from Riga Polytechnic Institute (RPI) in 2005, Mg..Sc.Ing. degree from Riga Technical University (RTU) in 2007, from 2008 he is $\mathrm{PhD}$ student.

Address: Kronvalda blv.,1, LV-1010, Riga, Latvia

Phone: +371 26161738, fax: +371 7089931

E-mail: olegs.borscevskis@ latvenergo.lv
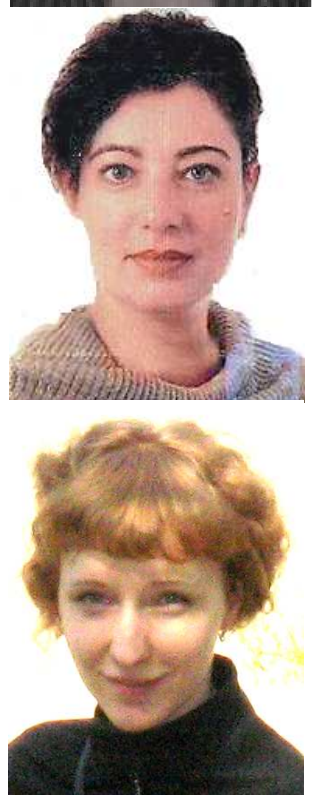

Lubov Kozireva received B.Sc. degree in electrical engineering from the Riga Technical University, Riga, Latvia, in 2008.

She is an Mag. student at Riga Technical University, Power Engineering Institute, Riga, Latvia.

Address: Kronvalda blv., 1, LV-1010, Riga,

Latvia

Phone: +371 28307721,

E-mail: luba1302@inbox.lv 